Journal of Current and Advance Medical Research

January 2020, Vol. 7, No. 1, pp. 1-2

http://www.banglajol.info/index.php/JCAMR

ISSN (Print) 2313-447X

ISSN (Online) 2413-323X

NLM Catalog ID 101673828

DOI: https://doi.org/10.3329/jcamr.v7i1.46421

EDITORIAL

OPEN 2 ACcess

\title{
Novel and Essential Concept of Pharmacovigilance: Bangladesh Perspective
}

\author{
Andalib Mustafa Iqbal Ira
} Associate Professor, Department of Pharmacology, National Institute of Cardiovascular Diseases, Dhaka, Bangladesh; Email:
andalibira0104@gmail.com; Cell no.: + +8801713121793

Each physician knows about drug reaction. When a drug reaction happens the event can be life threatening. After marketing of a medicine or drug (synonymously used though not same) there is a every chance of unpredictable fatal reaction. Pharmacovigilance, scientifically works in this sector.

Pharmacovigilants are struggling about detection, assessment, understanding and prevention about medicine or drug related problems. There are so many medicines are launched in every year. Before marketing all medicines are scientifically investigated but there are some limitations. Let us focus on history. It was structured in a professional health field for risk benefit ratio. Bangladesh tries to introduce it in all level of medicine users.

Thalidomide disaster can be mentioned here as a keynote. In 1958 tablet thalidomide was marketed, in 1961 to 62 association between teratogenicity with thalidomide was proved. WHO defined ADR in 1968 and the science of pharmacovigilance was born. The 16th World Health Assembly adopted a resolution that reaffirmed the need for early action in regard to rapid dissemination on Adverse Drug Reactions. A WHO technical report followed a meeting in 1971. They set UPPSALA as a central monitoring cell in Sweden, a research university in the year 1978 .

Pre and post marketing safety of medicine monitoring information are academically studied here. Reports are published, that forms the basis of current International System for collaborating in WHO program. New database systems is developed and this is vigibase. In 2002, more than 65 countries have formed their own pharmacovigilance centre.
Within 2010, more than 11 million cases of ADR were reported to the WHO (ICSR). Now active members are 123 and associate members 29 , total members are 152. Bangladesh is 120th number, 119th is Bhutan and 121st is Afghanistan.

Clinical trials evaluate efficacy and toxicity of drugs but cannot provide information for larger untested populations with different characteristics from trial group (age, gender, state of health, ethnic origin); clinical trial often lack important information about rare but serious adverse reactions, chronic toxicity or interactions with other drugs.

Premarketing information about drugs are inevitably incomplete with regards to possible reactions.

In Bangladesh, there are so many patients receiving a large number of medicines with or without prescriptions but under reporting is a significant obstacles in this field. Data management is a vital part of Pharmacovigilance as there is continuous generation of patient safety data.

Adverse events information can be generated from various modes, for example, clinical trial, post marketing programs, spontaneous reports, literature or legal reports. This information is to be collected and reported to the regulatory authorities for analysis.

Clinicians, institutions, chamber practitioner or any medicine related personnel are very reluctant about reporting. They think that this type of information will create a negative impact on their profession. So at first they must be assured about confidentiality. 
This is absolutely about safety for patient and also awareness about drug related reactions, reporting will help to avoid further hazards not to harass any person. Reporting should be in a structured form and often it lacks. There are so many reporting but not a single one is complete.
[Journal of Current and Advance Medical Research, January 2020;7(1):1-2]

[Cite this article as: Ira AMI. Novel and Essential Concept of Pharmacovigilance: Bangladesh Perspective. J Curr Adv Med Res 2020;7(1):1-2] 